\title{
A abordagem instrumental para o estudo da integração da tecnologia na prática pedagógica do professor de matemática
}

\section{The instrumental approach for the technology integration in the pedagogical practice of the mathematics teacher study}

\author{
Marilena Bittar ${ }^{1}$
}

\begin{abstract}
RESUMO
Neste texto discutimos uma forma de investigação sobre a apropriação da tecnologia pelo professor de matemática e seu uso em sua prática pedagógica. Apresentamos a abordagem instrumental que fornece elementos teóricos apropriados para esse estudo. Esta teoria apoia-se em conceitos da psicologia, em especial na ideia de esquema definida por Piaget e utilizada por Vergnaud, na teoria dos campos conceituais. Serão abordados somente alguns elementos da teoria, os que permitem compreender o uso de um software nas aulas de Matemática. É dada especial atenção ao conceito de gênese instrumental e, para isso, à distinção entre artefato e instrumento, e entre instrumentalização e instrumentação. A partir destes elementos e da distinção que fazemos entre inserir e integrar a tecnologia na prática pedagógica do professor de matemática são apresentados resultados de uma pesquisa-ação realizada com professores dessa disciplina.

Palavras-chave: prática pedagógica de matemática; emprego de software; instrumento e artefato; gênese instrumental.
\end{abstract}

\footnotetext{
ABSTRACT

This paper deals with a certain way to investigate the mastering of technology by mathematics teachers and its use in their pedagogical practice. The

1 Doutora em Didática de Disciplinas Científicas. Professora Associada 3 da Universidade Federal de Mato Grosso do Sul, Brasil.
} 
instrumental approach which brings the suitable theoretical elements to this study is presented. This instrumental approach is supported by some psychological Piaget's constructs, specially that one of schemata that is also assumed by Vergnaud in his theory of conceptual fields. Only the theoretical elements that make possible the understanding of a software implementation at mathematics lessons will be exposed. Special attention is given to the concept of instrumental genesis in order to make the distinction between artifact and instrument, and between instrumentalization and instrumentation. Results of an action-research realized with mathematics teachers are described based on those theoretical elements and on the proposed difference between inserting and integrating technology into the pedagogical practice in the mathematics teaching.

Keywords: pedagogical practice in mathematics; software implementation; instrument and artifact; instrumental genesis.

\section{Introdução}

Diversas investigações realizadas nos últimos trinta anos mostram que a tecnologia pode contribuir de diferentes modos com o processo de ensino e aprendizagem da Matemática. Ela pode se constituir em uma ferramenta de auxílio à compreensão do raciocínio do aluno, de suas dificuldades e compreensões, além de ser uma poderosa ferramenta na elaboração de atividades que favoreçam a aprendizagem e até mesmo a individualização da aprendizagem, contribuindo com a autonomia do aluno (BITTAR, 2006; BITTAR, 2010). Entretanto, infelizmente, estes resultados estão, em sua maioria, longe da sala de aula; ou seja, as aulas de matemática continuam sendo dadas, majoritariamente, sem o auxílio da tecnologia. Em geral, os principais argumentos utilizados por professores ou diretores de escola, ou mesmo pesquisadores para esse fato, concentram-se em torno de dois motivos: falta de material e de condições adequados (salas, computadores, softwares, ...) e falta de preparo dos professores.

Mas o que significa o professor estar preparado para usar tecnologia em suas aulas? Será que é conhecimento da máquina (computador) e de aplicativos básicos? Isso parece ser insuficiente no que diz respeito às aulas de matemática. Então será que significa ter conhecimento de softwares próprios para o ensino de matemática? Em nossa experiência com a formação de professores, tanto inicial quanto continuada, percebemos que para um professor fazer uso de um software de matemática em suas aulas é preciso um pouco mais do que o conhecimento deste e algum domínio do computador. Muitas vezes, mesmo tendo participado 
de cursos específicos sobre o uso de tecnologia os professores não a incorporam em suas aulas. Assim, apesar de alguns esforços que têm sido feitos, há pouco uso efetivo de tecnologia informática no ensino de Matemática. Ou seja, na maioria das vezes em que um software de matemática é usado com os alunos não se trata de uma situação que provoque mudanças com relação ao saber.

Antes de continuar com esta discussão, é importante explicitar a distinção que fazemos entre o professor inserir e integrar o computador em sua prática pedagógica. Inserir um novo instrumento na prática pedagógica significa fazer uso desse instrumento sem que ele provoque aprendizagem, usando-o em situações desconectadas do trabalho em sala de aula. Assim, a tecnologia é usada como um instrumento extra, um algo a mais que não está de fato em consonância com as ações do professor. Isso é o que acontece na maioria das vezes que um professor leva seus alunos ao laboratório de informática. A integração desse instrumento na prática pedagógica do professor significa que ele passa a fazer parte do arsenal de que o professor dispõe para atingir seus objetivos. Implica em fazer uso do instrumento de forma que este contribua com o processo de aprendizagem do aluno, que lhe permita compreender, ter acesso, explorar diferentes aspectos do saber em cena. Assim como o material dourado e o ábaco permitem explorar diferentes características do sistema de numeração decimal (por isso mesmo devem ser usados simultaneamente no ensino deste conteúdo), a tecnologia deve ser usada com fins de permitir ao aluno ter acesso a propriedades ou a aspectos de um conceito; ou ainda a atividades matemáticas diferentes daquelas habitualmente tratadas no ambiente papel e lápis. Por exemplo, o Cabri-Géomètre permite que o aluno explore uma construção geométrica elaborando conjecturas, a partir da manipulação da figura construída, atividade possibilitada justamente pela característica de dinamismo do software.

Nesse texto nosso interesse é o de analisar as mudanças nas práticas dos professores a partir do momento em que passam a usar a tecnologia com seus alunos. Surge então a questão de como investigar, do ponto de vista teórico, o processo de integração da tecnologia pelo professor em sua prática pedagógica. Acreditamos que para esse tipo de investigação é necessário estudar cuidadosamente a relação do professor com a tecnologia no uso desta como instrumento de auxílio à sua prática.

Para isso, é necessário um referencial teórico que permita investigar as mudanças que ocorrem na prática do professor, e isso de um ponto de vista psicológico, ou seja, do ponto de vista dos esquemas desenvolvidos pelo sujeito em sua ação. Estamos usando esquemas no sentido dado por Vergnaud (1990; 2009), segundo o qual um esquema comporta sempre quatro elementos: antecipações do objetivo que ele quer atingir, regras de ação (que vão gerar a ação do sujeito), inferências (que permitem que o sujeito avalie suas ações) e invariantes 
operatórios (são do tipo proposição, função proposicional ou argumentos e que tornam operacional a ação do sujeito $)^{2}$. Apoiado em conceitos da psicologia, em especial na ideia de esquema definida por Piaget e utilizada e ampliada por Vergnaud (1990), Rabardel (1995) desenvolve a teoria da instrumentação que fornece elementos teóricos apropriados ao estudo da ação do sujeito, mediado por um instrumento. Essa é a teoria adotada para compreendermos o uso da tecnologia pelo professor.

A teoria da instrumentação permite investigar a ação com instrumentos no campo social e no campo científico; ou seja, não se aplica somente à educação. Ao contrário, encontramos diversas aplicações em outros campos de trabalho. Um exemplo é o trabalho desenvolvido por Ferreira (1995) sobre o uso de computadores no serviço bancário. Entretanto, essa teoria tem se mostrado bastante adequada para estudar também o uso da tecnologia em situações de ensino e aprendizagem (sejam elas fora ou dentro da escola, propriamente dita, como por exemplo, a educação à distância) (GOMES, 2001). Neste texto abordaremos alguns elementos da teoria que permitem compreender algumas características do uso de um software nas aulas de Matemática.

Quando falamos em esquemas na teoria da instrumentação, estamos pensando no sujeito que age sobre alguma coisa. Dessa forma, um esquema tem uma característica dinâmica, o que é fundamental para a definição e diferenciação entre artefato e instrumento feita por Rabardel $(1995 ; 1999)$.

$\mathrm{Na}$ abordagem instrumental, um artefato pode ser um meio material, como um martelo, uma enxada, ou um meio simbólico, como uma linguagem simbólica (linguagem algébrica, símbolos vetoriais etc.). $\mathrm{O}$ instrumento consiste do artefato acrescido de um ou vários esquemas de utilização desse artefato, esquemas esses construídos pelo sujeito.

Rabardel $(1995 ; 1999)$ fornece assim uma definição psicológica de instrumento, pois toma como base para tal o conceito de esquema. Um instrumento não existe "por si só"; o artefato se transforma em um instrumento para um determinado sujeito quando este o incorpora às suas atividades. Ou seja, em nosso caso, um artefato (por exemplo, um software) torna-se um instrumento para o professor, relativamente à sua prática pedagógica, quando ele o utiliza com seus alunos, em sua atividade de ensino.

É possível distinguir três ideias centrais na definição de instrumento, que esclarecem seu caráter dinâmico:

- cada sujeito constrói seus próprios esquemas de utilização, portanto, seu próprio instrumento, que difere do instrumento do "outro";

2 Para o leitor menos familiarizado com a teoria dos campos conceituais recomendamos a leitura de Vergnaud (1990). 
- a medida que o sujeito continua a manipular o instrumento, vai construindo novos esquemas que vão transformando o instrumento. Estes esquemas são modificados pelo sujeito de acordo com suas necessidades;

- um mesmo artefato dá origem a diferentes instrumentos construídos por diferentes sujeitos.

Tomemos, como exemplo, o caso de um software como o Cabri-Géomètre ou o SuperLogo. Consideremos um professor para o qual o software é desconhecido. Ao entrar em contato com este material que não conhece, não sabe manipular nem mesmo as ferramentas básicas, este software é, para este professor, um artefato. À medida que ele começa a desvendar o material, descobrir como ele funciona e elaborar situações de uso do software, o professor está desenvolvendo e agregando ao artefato esquemas de utilização e, então, o artefato é transformado, para este professor, em instrumento. Quanto mais ele usar este instrumento, mais esquemas podem ser construídos, agregados ao software e o professor terá, então, um novo instrumento.

Voltaremos a esta discussão no momento da apresentação de alguns resultados, mas já é possível perceber que uma noção central na teoria da instrumentação são os esquemas desenvolvidos pelos sujeitos: os esquemas de uso e os esquemas de ação instrumentada. Os esquemas de uso são relativos às tarefas ligadas diretamente ao artefato, tais como ligar o computador, localizar os aplicativos, e colocar atalhos na tela. Os esquemas de ação instrumentada são relativos às tarefas diretamente ligadas ao objeto da ação. Os esquemas de ação instrumentada vão, progressivamente, constituindo-se em técnicas que permitem resolver eficientemente certas tarefas ${ }^{3}$ (ARTIGUE, 2002). Por exemplo, se o objetivo é usar um editor de textos, então ao aprender a usar as ferramentas do aplicativo para realizar a tarefa (o objetivo da ação do sujeito), este estará desenvolvendo um esquema de ação instrumentada.

Vale salientar que o que é esquema de ação instrumentada para um sujeito em um determinado momento pode se transformar em esquema de uso, para esse mesmo sujeito em um momento posterior. Para caracterizar um esquema é preciso analisar seu estatuto na atividade do sujeito. Rabardel (1995) ilustra essa afirmação com o exemplo da ultrapassagem de um veículo para um condutor que está aprendendo a dirigir e, depois, quando ele já é motorista experiente.

3 O termo "tarefa" refere-se ao quarteto (tarefa, técnica, tecnologia, teoria) da praxeologia discutido por Chevallard (1992). Neste texto não entraremos nessa discussão; entretanto, o leitor interessado em ler sobre o uso concomitante desta teoria e da teoria da atividade com instrumentos, pode se reportar a Artigue (2002). 
No primeiro caso trata-se de um esquema de ação instrumentada e no segundo de um esquema de uso. Ou seja, quando o sujeito já sabe dirigir e usa o carro para se deslocar de um local a outro, os esquemas envolvidos nesta ação (automatizada) podem ser interpretados como esquemas de uso.

No centro da teoria da atividade instrumentada está o conceito de gênese instrumental, que consiste no processo de elaboração do instrumento pelo sujeito. É neste processo que reside o interesse central de nossa pesquisa sobre a integração da tecnologia pelo professor em sua prática pedagógica. Por esse motivo é importante compreender esse processo.

Participam do processo de gênese instrumental duas dimensões: a instrumentalização e a instrumentação.

\begin{abstract}
A instrumentalização concerne a emergência e a evolução dos componentes artefato do instrumento: seleção, reagrupamento, produção e instituição de funções, transformações do artefato [...] que prolongam a concepção inicial dos artefatos. A instrumentação é relativa a emergência e a evolução dos esquemas de utilização: sua constituição, seu funcionamento, sua evolução assim como a assimilação de artefatos novos aos esquemas já constituídos (RABARDEL, 1999, p. 210).
\end{abstract}

Fica assim mais claro que o instrumento não é algo pronto e acabado; ele pode ser elaborado e reelaborado pelo sujeito ao longo das atividades realizadas com o artefato, agora um instrumento, uma vez que já sofreu a ação do sujeito.

Relativamente ao uso de tecnologia na prática pedagógica do professor, quando falamos em integração, estamos querendo dizer um professor que se torna autônomo nesse uso. Ou seja, estamos nos referindo a uma integração crítica. Nesse sentido, a abordagem instrumental oferece um referencial que permite avançar nessa questão, como é possível ver em Artigue (2002). Investigar a gênese instrumental em situação de formação de professores é investigar como o professor cria os esquemas para o uso da tecnologia e como essa tecnologia vai transformar sua prática pedagógica de forma a contribuir com a aprendizagem do aluno.

A seguir apresentamos uma pesquisa desenvolvida com professores que ensinam matemática cujo quadro teórico utilizado para compreender as posições dos sujeitos com relação à tecnologia foi a teoria da instrumentação. 


\section{Formação de professores: um projeto de pesquisa-ação}

O professor que está atuando na sala de aula, na maioria das vezes, não conhece as possibilidades da tecnologia para a aprendizagem. E, em geral, quando ele entra em contato com ela isso se dá sem que se leve em consideração a realidade na qual ele está inserido. Estas experiências evidenciam a necessidade de uma formação continuada que parta da experiência do professor. Por isso, é importante que a formação do professor seja feita em serviço, se possível em seu local de trabalho, vivenciando suas dificuldades e problemas do dia a dia e durante um tempo que seja suficiente para o amadurecimento das discussões acerca das situações vivenciadas. Dessa forma, não é possível pensar em mudanças na prática pedagógica a partir de situações isoladas da realidade do professor. Além disso, o professor não deve ser agente recebedor de práticas a serem repetidas: esse é um paradigma ultrapassado. Segundo Warde e Carvalho (2000, p. 17):

Com as fugas às abordagens althusserianas, os estudos etnográficos e da nova sociologia da educação, alimentaram - cada um a seu modo investigações que repuseram o professor no centro das práticas escolares, como sujeito que as inaugura e as funda. Partindo dessa perspectiva, criouse o campo propício para a reafirmação contemporânea do professor como epicentro das transformações da escola, das propostas curriculares, sendo ele a expressão da 'nova-subjetividade' em emergência.

Acreditamos, portanto, que o professor não pode ser agente passivo em uma pesquisa, sujeito a ser modificado pela pesquisa, mas sim um sujeito que tem conhecimentos e, sobretudo, necessidades que devem ser consideradas. É nesse sentido que cremos na pesquisa-ação como uma das possibilidades de trabalho que pode ser realizado com o professor de forma a ser significativo para ele.

Os professores que vivenciam processos de pesquisa-ação têm a possibilidade de refletir sobre as suas próprias práticas, sua condição de trabalhador, bem como os limites e possibilidades do seu trabalho. Nesse sentido, ela se constitui em uma estratégia pedagógica de conscientização, análise e crítica e propõe, a partir da reflexão propiciada na interlocução com os pesquisadores-observadores e na participação nas discussões com o grupo de pesquisa, alterações de suas práticas, sendo delas os autores (PIMENTA, 2005, p. 527). 
Tendo como pressuposto esta perspectiva teórica e as pesquisas anteriormente realizadas por nós, propusemos e desenvolvemos, nos anos de 2006 e 2007, uma pesquisa nos moldes da pesquisa ação (THIOLLENT, 1986). Nessa modalidade de pesquisa todos os participantes têm papel ativo na produção do conhecimento e parte-se sempre dos problemas levantados pelos participantes da pesquisa e não por um ou alguns coordenadores. Acreditamos que a constituição de grupos compostos por pesquisadores e professores pode/deve trazer subsídios para a integração da tecnologia na prática pedagógica do professor. Formamos então um grupo com o objetivo de investigar a integração da tecnologia na prática pedagógica do professor que ensina Matemática na Educação Básica. Este grupo foi formado por pesquisadores e professores atuantes nos diversos níveis de escolaridade que lecionam matemática. $\mathrm{O}$ trabalho foi desenvolvido em dois anos, e recebeu financiamento do CNPq. Do ponto de vista da prática pedagógica dos professores, queríamos construir juntos uma nova prática, ou o embrião de uma nova prática, a partir de questões trazidas pelos participantes do grupo. Para investigar essa nova prática, tentamos identificar e estudar os esquemas desenvolvidos pelos participantes da pesquisa, o que permitiu analisar a relação do professor com o artefato ou instrumento. Cabe ainda salientar que o Grupo foi constituído por professores com licenciatura em matemática ou em pedagogia.

A coleta de dados foi feita de diferentes formas, sendo que as principais delas foram as anotações dos participantes durantes as reuniões em seus cadernos de bordo e as atas de cada reunião. Estas atas eram redigidas por um membro do Grupo que, em seguida, submetia a todos os participantes seu conteúdo, procedimentos consonantes com a metodologia da pesquisa-ação.

\section{Relação dos professores com a tecnologia no início do projeto}

O Grupo de Estudos foi composto por trinta pessoas, sendo oito pesquisadores ligados à universidade (professores ou alunos de doutorado ou mestrado) e vinte e dois professores da educação básica. Ao longo do projeto, esse número variou. Iniciamos o trabalho com reuniões cujo objetivo era o de discutir o que o Grupo pensava sobre o uso de tecnologia nas aulas de matemática. Analisando as discussões, observamos diferentes posições dos sujeitos relativamente a seu conhecimento sobre tecnologia. Alguns não sabiam manipular aplicativos básicos tendo dificuldades em manusear o mouse ou usar um editor de textos, entre outras. Assim, para esses sujeitos o computador era um artefato. Entretanto, 
alguns sujeitos eram familiarizados com o computador, sabendo usá-lo para suas necessidades básicas, mas não haviam desenvolvido esquemas para o uso em sua prática pedagógica. Por fim, outros poucos participantes já haviam dado aulas usando um software. Podemos assim dizer que estes já haviam desenvolvido esquema de ação instrumentada relativamente ao software que haviam utilizado. Mas, será que esses esquemas de ação instrumentada significavam que houve integração da tecnologia na prática destes professores, ou seria somente a inserção? É o que analisamos adiante.

Ao final desta primeira fase, o Grupo optou pelo estudo do tema softwares educativos e suas possibilidades para a aprendizagem matemática por meio da leitura de textos e posterior discussão. Esta decisão partiu da constatação, dos próprios membros do Grupo, da necessidade de aprofundar os conhecimentos de todos sobre esta temática.

A partir desta atividade de estudo, passou-se à fase seguinte, a do estudo e análise de um software que poderia contribuir com a aprendizagem da Matemática. O Grupo escolheu trabalhar com o SuperLogo. Cabe salientar que, inicialmente, no projeto proposto ao $\mathrm{CNPq}$, estava previsto que, no momento de estudar softwares, haveria divisão em subgrupos de estudo levando em consideração os diferentes segmentos nos quais os professores trabalhavam (desde a educação infantil até o ensino médio e educação superior). Entretanto, ao ser proposta esta separação, os participantes do grupo disseram preferir permanecer juntos, alegando acreditar ser mais produtivo e que os que conheciam menos matemática poderiam ser ajudados pelos outros. Imediatamente a proposta foi aceita por todos. Os professores formados em matemática alegaram gostar de permanecer junto com os pedagogos por poderem aprender com estes coisas que jamais haviam pensado, relacionadas à forma como as crianças aprendem, por exemplo.

Como o SuperLogo permite elaborar atividades para trabalhar com os diversos níveis de escolaridade, ele foi o escolhido para ser explorado por todos. Nesse trabalho, realizado em um laboratório de informática da universidade, não foi dada aula sobre o software ou sobre como usar o software: foram apenas explicados os comandos básicos; em seguida, o grupo todo começou a exploração do material, cada um tentando pensar em como seria possível usá-lo em suas aulas.

Nas discussões procurava-se observar como utilizar a informática para favorecer a aprendizagem do aluno. Assim, quando um professor pensava uma atividade essa era compartilhada com o restante do Grupo para discussão, momento em que todos levavam em consideração as discussões realizadas anteriormente sobre o uso de um software nas aulas de matemática. As observações dos participantes do Grupo eram cada vez mais voltadas para algo que pudesse 
significar um diferencial em sua prática pedagógica melhorando a aprendizagem de seus alunos. Nesta fase, uma professora das séries iniciais elaborou e aplicou uma atividade com seus alunos usando o SuperLogo, segundo ela "por ter gostado muito do software e achar que podia usá-lo". Ela relatou essa experiência no Grupo o que permitiu uma discussão sobre os objetivos didáticos da professora, sobre as atividades que ela propôs e, inclusive, sobre os conceitos matemáticos trabalhados.

Cada participante foi, assim, desenvolvendo seus esquemas de uso e de ação instrumentada relativos a esse material. O artefato se transformava em instrumento que, com a continuidade da exploração, transformava-se em outro instrumento diferente para cada sujeito. Para alguns se tratava de, primeiro, familiarizar-se com o SuperLogo, caracterizando-se assim o desenvolvimento de esquemas de uso do software. Para outros, que já tinham tido contato com o software e sabiam manipulá-lo, o trabalho ocorreu em torno de pensar como ele poderia ser usado em suas aulas de forma a contribuir para a aprendizagem de seus alunos. Ou seja, estes professores estavam desenvolvendo esquemas de utilização do SuperLogo.

É interessante observar que alguns professores manifestaram explicitamente perceber uma diferença entre o trabalho que já faziam com a tecnologia e o que estavam passando a fazer com a participação no Grupo.

\begin{abstract}
Antes de participar aqui do grupo, eu simplesmente levava meus alunos no laboratório por que... Tinha que levar, e eu bolava alguma coisa para eles fazerem ali. E não tinha nada a ver com o conteúdo que eu estava dando, aplicando em sala. Então, eu lançava uns desafios... Ou então... Um teste de raciocínio... Uma dinâmica... [...] Uma planilha no Excel, que eles olhavam no Excel e... respondiam. Então, não tinha muita coisa a ver com... [...] a matéria que eu estava dando... [...] Eu não sabia [...] direito como procurar... como encontrar estes softwares... como utilizar. [...] Eu não tinha me familiarizado com isso ainda. Foi depois que eu comecei a participar do Grupo (Pedro ${ }^{4}$, 28/08/2007).
\end{abstract}

A fala de Pedro demonstra que ele começa a integrar a tecnologia em suas aulas. Antes do Grupo, como ele mesmo afirma, a tecnologia estava inserida em suas aulas. De fato, o uso que ele fazia da tecnologia não era articulado com suas ações usuais; eram desconectadas do trabalho que ele realizava. Isso pode ser confirmado na continuidade de sua fala:

4 Nome fictício do professor. 
Trabalhar com o computador era isso: que você usaria o computador pra aplicar uma coisa que você [o professor explicando para o aluno] já tinha estudado... Na sala de aula, no lápis e papel. Primeiro você fazia em lápis e papel e depois você ia pro computador pra ver como que ficava lá dentro. Agora não. Agora na minha ideia você pode muito bem ir pro computador, construir o conhecimento e depois se precisar usar o lápis e o papel. [...] $\mathrm{Eu}$ estou deixando de usar a ferramenta giz e apagador pra usar mouse, teclado e software. Eu acho que é isso aí... Eu acho que essa é a principal mudança. [...] Hoje eu estou mudando esse meu conceito. [...] Você pode trabalhar totalmente ao contrário: você pode levar os alunos pro laboratório, usar ali... Fazer com que eles [...] construam um conhecimento ali de uma nova matéria, de uma nova... De um novo conteúdo, e depois volta, pra, pra realizar as contas no, no papel e lápis. [...] (Pedro, 28/08/2007).

Pedro começa a questionar sua forma de uso da tecnologia. Nessa fala de Pedro é possível observar a presença de um paradigma bastante presente entre os professores, o de que a tecnologia serve para ilustrar um conceito visto, ou para despertar o interesse do aluno. Primeiro é dada a matéria na sala de aula e depois se vai para o laboratório de informática. Somos contrários a essa postura: um conteúdo pode ser iniciado no laboratório. Aliás, defendemos um trabalho que articule papel e lápis com o computador. Por exemplo, o professor pode elaborar atividades que levem os alunos a elaborar uma determinada conjectura e depois passar este resultado para o caderno. Ou seja, a tecnologia é usada para levar o aluno a elaborar conhecimento.

Além do fato de começarem a perceber como a tecnologia pode ser usada para levar o aluno a elaborar conhecimento, os professores (alguns deles) começaram também a esboçar traços de autonomia ao perceberem o que, de fato, está em jogo ao usar determinado software com os alunos. Isso fica claro no excerto a seguir, da fala do professor Pedro.

\begin{abstract}
Ah, hoje, eu pelo menos... Não vou dizer que hoje eu to fazendo do jeito certo, mas eu já to pelo menos no caminho certo, não é? Já sei como fazer, não é? Agora, a questão de como fazer eu já sei. Agora, o que fazer vai depender da aula, não é? Aí depende da aula. Por que agora eu consigo... Se eu não consigo achar, se eu não tenho resposta eu sei pelo menos onde procurar a resposta de como fazer e o que fazer (Pedro, 29/04/2008).
\end{abstract}

Podemos assim dizer que esse professor está desenvolvendo o processo de instrumentação relativamente ao uso da tecnologia em suas aulas. Poderíamos 
dizer que isso ocorreu, mais especificamente com relação ao SuperLogo; mas, analisando sua fala aqui transcrita (e outras, ao longo dos dois anos de trabalho), podemos também inferir que, no caso deste professor, o objetivo maior do projeto foi atingido: o de que cada professor torne-se capaz de analisar criticamente um material que lhe seja oferecido, pensando sempre em como pode ser ele usado para contribuir com o processo de aprendizagem de seus alunos.

Um fato que mostra claramente o início da integração da tecnologia pelo professor é o seguinte: durante a fase de trabalho com o SuperLogo, os participantes sentiram necessidade de estudar alguns conceitos de geometria. Isso ocorreu justamente em função da análise do software e da elaboração de atividades levadas a cabo com ele. O questionamento sobre estas atividades e o quão elas seriam adequadas para serem realizadas, mostra que os participantes mostravam-se claramente na fase de instrumentação, desenvolvendo esquemas de ação instrumentada para o uso desse material em sala de aula.

A fase seguinte do trabalho consistiu da preparação de sequências didáticas (BROUSSEAU, 1986; 2008) usando a tecnologia. Foram constituídos três grupos sendo que cada um deveria elaborar uma sequência a ser aplicada no nível de escolaridade escolhido. Um grupo se dedicou ao estudo e uso da calculadora nas séries iniciais do ensino fundamental; outro, ao Cabri-Géomètre ${ }^{5}$ com atividades a serem aplicadas com alunos do ensino médio, e o terceiro ao SuperLogo, também com atividades para crianças das séries iniciais. Nesta fase foi possível observar com mais detalhes o surgimento de esquemas de utilização por parte dos participantes do Grupo. À medida que o participante aprendia a manusear um software, ele passava, com as discussões e objetivos a serem alcançados, a tentar elaborar atividades que favorecessem a aprendizagem de seus alunos; assim, assistia-se o surgimento de esquemas de utilização deste material.

Apesar de o trabalho ser coletivo, não se criavam os mesmos esquemas de utilização, o que tinha muita relação também com toda a história de vida do professor. Passou-se da fase de aprendizado da máquina e do software para a discussão sobre como incorporar este material nas aulas e isto, de forma prática, uma vez que estavam sendo elaboradas, conjuntamente, atividades a serem utilizadas com os alunos. Uma questão importante a salientar na dinâmica do processo desenvolvido é que o mesmo não acabava com a aplicação da sequência na sala de aula; ao contrário, esta aplicação era discutida no Grupo com objetivo, não somente de compartilhar as experiências, mas também de avaliar o que foi desenvolvido.

5 Parte das ações realizadas pelo grupo que estudou o Cabri-Géomètre são relatadas e analisadas em Silva (2009). 


\section{Algumas conclusões}

O primeiro ponto que queremos abordar é o da mudança de postura dos participantes da pesquisa, relativamente ao uso da tecnologia nas aulas de matemática. A ideia de que esse material deve ser utilizado de modo a provocar a aprendizagem, a levar o aluno a construir seu conhecimento, parece ter tomado conta do Grupo. Nos últimos meses dos dois anos de pesquisa, era comum presenciarmos discussões entre participantes do Grupo acerca de alguma atividade que algum deles havia preparado, discussões essas que giravam em torno das seguintes questões: por que você vai fazer (ou fez) dessa forma? Qual a vantagem de usar a informática? Não podia ser no papel e lápis? O que modificaria, nesse caso?

Pudemos também observar que os momentos de discussão coletiva, presentes ao longo dos dois anos de trabalho, propiciavam novas aprendizagens, ou seja, novos esquemas eram produzidos, esquemas esses diferentes para cada participante. Nesses momentos, ficava muito claro que eles se encontravam em diferentes estágios no que se refere ao uso da tecnologia nas aulas de matemática, porém todos haviam passado por mudanças desde a entrada no Grupo. Não se trata de querer ou imaginar que seja possível, após um tempo de trabalho conjunto, ou mesmo de um curso, ter participantes com a mesma posição relativamente a um determinado saber. O que está em jogo é justamente o que cada um deles incorpora em sua ação a partir do trabalho realizado.

Em segundo lugar queremos discutir a pertinência da teoria que adotamos para estudar a incorporação da tecnologia na prática pedagógica do professor que ensina Matemática. As análises que realizamos mostraram que, de fato, a abordagem instrumental permite melhor compreender como o professor apreende e incorpora a tecnologia em sua prática pedagógica. Investigar essa incorporação significa investigar o processo de gênese instrumental, quer dizer, como se dá a elaboração do instrumento pelo sujeito. É importante salientar que essa abordagem teórica também pode ser e é utilizada para investigar a aprendizagem com instrumentos, ou seja, para estudar como o aluno aprende na presença de instrumentos. Nessa perspectiva, a teoria antropológica do didático (CHEVALLARD, 1992) parece complementar a teoria da instrumentação, ao menos quando investigamos a aprendizagem matemática, como mostra Artigue (2000). É nessa direção que nossas pesquisas sobre o uso da tecnologia estão voltadas atualmente. 


\section{REFERÊNCIAS}

ARTIGUE, M. Learning mathematics in a CAS environment: The genesis of a reflection about instrumentation and the dialectics between technical and conceptual work. International Journal of Computers for Mathematical Learning, v. 7, n. 3, p. 245-274, 2002.

BITTAR, M. Possibilidades e dificuldades da incorporação do uso de softwares na aprendizagem da matemática. O estudo de um caso: o software Aplusix. In: III SIPEM SEMINÁRIO INTERNACIONAL DE PESQUISA EM EDUCAÇÃO MATEMÁTICA. Anais... Recife: Sociedade Brasileira de Educação Matemática, 2006. p. 1-12.

. A escolha do software educacional e a proposta pedagógica do professor. In: COSTA, N. M. L. de; BELINE, W. (Orgs.). Educação matemática, tecnologia e formação de professores: algumas reflexões. Campo Mourão: Editora FECILCAM, 2010. p. 215-242.

BROUSSEAU, G. Fondements et méthodes de la didactique des mathématiques. Recherches em Didactique des Mathématiques, v. 7, n. 2, p. 33-115, 1986.

. Introdução ao estudo da teoria das situações didáticas - conteúdos e métodos de ensino. São Paulo: Editora Ática, 2008.

CHEVALLARD, Y. Concepts fondamentaux de la didactique: perspectives apportées par une approche anthropologique. Recherches en Didactique des Mathématiques, v. 12, n. 1, p. 73-111, 1992.

FERREIRA, M. C. Infomatisation bancaire et activité instrumentée: De l'aide au conflit d'interaction instrumentale. Mémoire, D.E.A. Paris: École Pratique des Hautes Études, 1995.

GOMES, A. S. Développement conceptuel consécutif a l'activité instrumentée L'utilisation d'un système informatique de géométrie dynamique au collège. Lille: Les Presses Universitaires du Septentrion, 2001. v. 1.

PIMENTA, S. G. Pesquisa-ação crítico-colaborativa: construindo seu significado a partir de experiências com a formação docente. Educação e Pesquisa, v. 31, n. 3, p. 521-539, 2005.

RABARDEL, P. Les hommes et les technologies: une approche cognitive des instruments contemporains. Paris: Armand Colin, 1995.

. Éléments pour une approche instrumentale en didactique des mathématiques. In: BAILleul, M. (Ed.). Actes de la Xème Ecole d'Été en Didactiques des 
Mathématiques. Houlgate: IUFM de Caen, 1999. p. 202-213.

SILVA, X. J. Mudanças na prática docente do professor de matemática com a inserção do computador: a trajetória de três professores participantes de um grupo de pesquisaação. Dissertação (Mestrado em Educação Matemática) - Universidade Federal de Mato Grosso do Sul, Campo Grande, 2009.

THIOLlENT, M. Metodologia da pesquisa-ação. São Paulo: Cortez, 1986.

VERGNAUD, G. La théorie de champs conceptuels. Recherches en Didactique de Mathématiques, v. 10, n. 23, p. 133-170, 1990.

. O que é aprender? In: BITTAR, M.; Muniz, C. A. (Orgs.). A aprendizagem matemática na perspectiva da teoria dos campos conceituais. Curitiba: Editora CRV, 2009. p. 13-26.

WARDE, M. J.; CARVALHO, M. M. C. de. Política e cultura na produção da história da educação no Brasil. Contemporaneidade e Educação, n. 7, p. 9-33, 2000. 
